\title{
Reacciones adversas a la vacuna contra influenza A (H1N1) en trabajadores de salud de una institución pública peruana
}

\author{
Adverse reactions to A (H1N1) influenza vaccine in a Peruvian healthcare workers
}

public institution

\author{
Pedro P. Álvarez-Falconí ${ }^{1,2,3}$, Luis Miguel Sánchez-Hurtado ${ }^{4,5}$ \\ Oficina Inteligencia Sanitaria, Centro Nacional de Salud Pública, Instituto Nacional de Salud del Perú. \\ ${ }^{2}$ Médico Farmacólogo, Ex Director General, Centro Nacional de Control de Calidad (Medicamentos). \\ ${ }^{3}$ Profesor Principal, Universidad Nacional Federico Villarreal, Lima, Perú. \\ ${ }^{4}$ Médico, Ex Director, Hospital Nacional Arzobispo Loayza. \\ ${ }^{5}$ Profesor Principal, Universidad Nacional Mayor de San Marcos, Lima, Perú.
}

\begin{abstract}
Resumen
Introducción: En abril de 2009 se produjo un brote de influenza en la frontera de México y EE UU por el nuevo virus A(H1N1) 2009. La pandemia no fue severa y la vacuna aplicada en diversos paises produjo diversas reacciones adversas a medicamentos (RAM). Objetivos: Evaluar la posible relación entre las RAM notificadas espontáneamente y la vacunación en trabajadores de salud de un instituto. Así mismo, identificar tópicos afines a las RAM por dicha vacuna. Diseño: Estudio prospectivo y descriptivo basado en la notificación espontánea. Institución: Local central del Instituto Nacional de Salud en Lima. Participantes: Trabajadores de salud. Metodología: Las RAM notificadas espontáneamente fueron registradas en Hojas RAM. Se aplicó un algoritmo para buscar una relación causa-efecto. Principales medidas de resultados: Reacciones adversas a la vacuna influenza $\mathrm{A}(\mathrm{H} 1 \mathrm{~N} 1)$. Resultados: Hubo tres notificaciones espontáneas entre 148 trabajadores de salud vacunados (2\%) contra la influenza $A(H 1 N 1) 2009$. La relación causa-efecto fue 'cierta' para fiebre y fatiga y 'posible' para afecciones respiratorias en tres mujeres (faringitis aguda, catarro nasal agudo, bronquitis catarral). Conclusiones: Entre los pocos trabajadores de salud que presentaron RAM, las afecciones respiratorias con una relación considerada 'posible' podría interpretarse que las mujeres serían más sensibles para esa RAM comparadas con los varones. Las RAM fiebre y fatiga alcanzaron una relación considerada 'cierta'. La menor cantidad de infectados en personas de tercera edad en el país y en otros podria explicarse por la presencia de 'anticuerpos protectores' en ellos.
\end{abstract}

Palabras clave: Reacción adversa a medicamento, influenza, pandemias, vacuna A(H1N1) 2009, Perú.

\section{Abstract}

Introduction: In April 2009 an influenza outbreak caused by a new virus, influenza A (H1N1), started in the Mexican-American border. Later this outbreak became pandemic but not as severe as initially thought; immunization programs were developed, and vaccines used led to vaccine adverse events (VAE). Objectives: To assess a possible relationship between spontaneously reported VAE and influenza A H1N1 vaccination in an institute's healthcare workers. Design: Prospective and descriptive study based on spontaneous notification. Setting: Instituto Nacional de Salud headquarters, Lima, Peru. Participants: Healthcare workers. Methods: Spontaneously notified VAE were recorded in specially designed sheets. An algorithm was used in order to assess a cause-effect relationship. Main outcome measures: Influenza $\mathrm{A}(\mathrm{H} 1 \mathrm{~N} 1)$ vaccination adverse events. Results: There were three spontaneous reports in 148 vaccinated healthcare workers (2\%). Cause-effect relationship was deemed as 'certain' for cases presenting with fever and fatigue, and as 'possible' for cases presenting with respiratory involvement (acute pharyngitis, nasal catarrh, acute and catarrhal bronchitis). Conclusions: Among the few healthcare workers who developed VAE, respiratory involvement reported in three women and considered as having a 'possible' cause-effect relationship may be interpreted as women being more susceptible to this event compared to men. Fever and fatigue were considered as having 'certain' cause-effect relationship. The smaller number of elderly infected persons reported in this country and in others may be explained by the presence of 'protective antibodies' in these persons.

Key words: Vaccine adverse event, influenza, pandemics, influenza A (H1N1) 2009, Peru.

An Fac med. 2011;72(3):169-75

\section{INTRODUCCIÓN}

La influenza es una enfermedad febril que afecta las vías respiratorias, tendiendo a producir epidemias y aún pandemias, especialmente en el invierno, pudiendo llevar a complicaciones y muerte, aunque también producir una enfermedad moderada y aún leve.
En abril del año 2009, primavera del hemisferio norte, se produjo un brote epidémico de influenza en la frontera de México con EE UU, ocasionado por un virus nuevo. Pocos años antes, la Organización Mundial de la Salud (OMS) había informado sobre una probable pandemia de influenza de letalidad alta, que no se presentó, por lo que ello hizo presumir que este virus nuevo influenza causaría morbilidad y mortalidad mayor que una influenza estacional, provocando temores e incertidumbres muy grandes, inclusive por una segunda ola de gran letalidad. La propagación de ese virus nuevo influenza hacia más de cien países, mas no la severidad de la infección $^{(1)}$, ocasionó que la OMS elevara la 
alerta de pandemia al más alto nivel el 11 de junio de 2009.

Dicha situación hizo recordar que en EE UU, en 1976, hubo un brote de influenza en personal militar de Fort Dix, New Jersey, con alrededor de 200 casos y un fallecido por el nuevo virus $\mathrm{A}(\mathrm{H} 1 \mathrm{~N} 1) / \mathrm{New}$ Jersey/76. Para evitar que circulara en la población civil, a pesar que el número reproductivo básico calculado para el virus fue más bajo que una influenza estacional, se cumplió una campaña que vacunó a 45 millones de personas para esa posible epidemia que nunca se produjo. La vacuna para ese virus produjo reacciones adversas a medicamentos (RAM) graves ${ }^{(2)}, 532$ casos de síndrome de Guillian-Barré (G-B) y 32 fallecidos. Los medios sociales la denominaron 'epidemia de invento', 'error', que obligó a la suspensión de la campaña, con el costo social señalado y el económico de cientos de millones de dólares pagados por el gobierno para indemnizar a las víctimas.

El 15 y el 17 de abril de 2009, los Centers for Disease Control (CDC) de EE UU identificaron ese virus nuevo de influenza, a partir de las muestras de dos niños enfermos residentes en el sur de California, sin relación epidemiológica entre ellos, resultando las cepas genéticamente similares en ambos pacientes. Era un virus influenza de origen porcino ${ }^{(3)}$, que había incorporado genes de virus porcino, aviar y humano, así como segmentos de genes del linaje de América del Norte y del linaje del virus influenza porcino euroasiático ${ }^{(4)}$, y que había roto la barrera de transmisión entre las especies. Fue catalogado como A/California/04/2009 (H1N1), nomenclatura que incluye el tipo de virus influenza $(A, B, C)$, origen geográfico, número de cepa, año de aislamiento y subtipo de virus basado en la antigenicidad de la hemaglutinina (H1) y neuraminidasa (N1). Este nuevo virus quedó identificado como influenza A(H1N1) 2009, responsable de la pandemia del 2009. Cerca de dos semanas antes, el Ministerio de Salud de México había informado del incremento de casos de influenza en la esta- ción del año en que habitualmente no ocurría, enviando muestras al National Microbiology Laboratory, Public Health Agency de Canadá, que identificó el 23 de abril de 2009 el mismo virus aislado por el CDC a los dos pacientes de California.

En México y EE UU, la epidemia afectó especialmente a jóvenes, en una media de 44 años ${ }^{(5)}$. Los mayores de 65 años no fueron los más afectados, a diferencia de las influenzas estacionales. Las manifestaciones en $642 \mathrm{ca}$ sos confirmados fueron de una enfermedad respiratoria con fiebre $(94 \%)$, tos $(92 \%)$, dolor de garganta $(66 \%)$ y dolor muscular, clínicamente similar a una influenza estacional ${ }^{(6)}$, con diarrea ( $25 \%)$ o vómito $(25 \%)$, que se presentaba desde una infección autolimitada a una enfermedad grave.

La información sobre el número relativamente menor de infección por la influenza pandémica A(H1N1) 2009 en personas adultas de 65 años a más hizo presumir una inmunidad preexistente por anticuerpos protectores, no resultantes de las vacunaciones de influenza estacionales de años anteriores $(2005,2006,2007,2008)$, porque ninguna había protegido contra la influenza pandémica A(H1N1) $2009{ }^{(7)}$, en grupo alguno de edades ${ }^{(8)}$, lo cual era de esperar por la divergencia genética entre los virus de origen humano en tales vacunas para influenza estacional y el virus de origen porcino de la influenza pandémica $A(H 1 N 1)$ 2009. En la búsqueda de la explicación, en sueros almacenados en EE UU, se encontró que una proporción importante de adultos mayores tuvo anticuerpos de reacción cruzada preexistentes o protectores, en mayor proporción en los nacidos antes de $1950^{(9)}$, probablemente por la vacunación contra el virus influenza porcina A/New Jersey/1976 que habían recibido o por haber tenido contacto con el virus de la pandemia de influenza de 1918. En ambos casos, los virus fueron genéticamente similares al virus influenza A(H1N1) 2009, lo que podría explicar que en tales adultos mayores se encontrara protección inmunitaria, como si se activara la memoria celular inmunitaria produciendo anticuerpos protectores o infecciones menos graves. Una respuesta cruzada protectora ha sido mencionada aunque con virus de otras especies ${ }^{(10)}$.

En Lima, los adultos mayores parecieron no enfermar gravemente o no fueron afectados con frecuencia. La Dirección General de Epidemiología (DGE) del Ministerio de Salud editó la "Situación actual de la influenza A(H1N1), al 09 de noviembre 2009", donde la edad promedio de los casos confirmados fue 21 años; de $8900 \mathrm{ca}$ sos, $10 \%$ tenía entre 20 a 24 años y $2 \%$ 65 años a más, siendo mujeres el 52\% del total; la edad promedio de defunciones fue 36 años, de 0 a 9 años fue $17 \%$, de 50 a 59 años $18 \%$ y de 60 años a más $14 \%$.

En un hospital nacional en Chiclayo, ciudad a $770 \mathrm{~km}$ al norte de Lima, la menor tasa de morbilidad de hospitalizados fue de mayores de 64 años, con la estancia hospitalaria más corta ${ }^{(11)}$. No se conoce de la presencia de anticuerpos protectores para explicar esta posible inmunidad preexistente. Para sustentarla tendría que admitirse que la pandemia de influenza de 1918 alcanzó significativamente a Perú. Otra hipótesis es que tales adultos mayores fueron infectados por la epidemia de influenza de 1951 en Perú, considerando que ese virus en su historia evolutiva ${ }^{(12)}$ tuvo relación con el virus de $1918^{(13)}$ y en consecuencia con el virus epidémico A(H1N1) 2009, por su origen porcino. Cuando una situación de inmunidad preexistente se advierte, puede admitirse que la persona ha estado expuesta a un virus similar, en particular una infección. La protección en adultos mayores parece fue un denominador común, por lo que al menos un sector de la población mundial estaba protegida, no fue susceptible o fue menos susceptible a la pandemia 2009, lo que no ocurrió en 1918 con millones de muertos. Esa pandemia y otras epidemias o pandemias subsecuentes con virus de componente porcino podrían haber contribuido a esa protección. 
En Lima, la Oficina de Inteligencia Sanitaria (OIS) del Centro Nacional de Salud Pública del Instituto Nacional de Salud (INS), emitió a fines de abril de 2009 un Informe ( $\mathrm{N}^{\circ}$ 016-2009-OIS. $\mathrm{CNSP} / \mathrm{INS}$ ) respecto al virus influenza $\mathrm{A}(\mathrm{H} 1 \mathrm{~N} 1)$ 2009, señalando que "coincidimos con la opinión" acerca que el virus "no es tan virulento como se pensaba inicialmente", que "no existe punto de comparación con otros virus de alta virulencia como el de influenza de 1918", y que "es una cepa de virus aparentemente benigna". La prueba del tiempo dio la razón a dicho Informe, porque si bien el brote produjo letalidad o manifestaciones severas, la enfermedad fue de gravedad similar a la de una influenza estacional ${ }^{(14)}$. La evaluación de la epidemia indicaba que producía una enfermedad leve en la mayoría de las personas ${ }^{(15)}$, con tasas bajas de hospitalización y de mortalidad en los adultos de 65 a más años, comparados con las anteriores pandemias. Fue básicamente de intensidad estacional; las defunciones que ocasionó fueron mayormente en personas de alrededor de 35 años que tenían un factor de riesgo, como lo tenían los adultos mayores fallecidos, siendo a pesar de ello de virulencia baja ${ }^{(16)}$.

En América del Sur, con su invierno iniciando, se enfrentó la pandemia sin vacunas por la imposibilidad de producirlas a tiempo. La Food and Drug Administration de EE UU autorizó la producción de la vacuna monovalente usando la cepa de influenza A/California/7/2009 sin adyuvante. La producción de la vacuna cumplió con los requisitos convencionales y ensayos clínicos correspondientes; fueron probadas para seguridad e inmunogenicidad, estando completas para su empleo en alrededor de cuatro meses, siendo utilizadas primero en el hemisferio norte.

La Agencia Europea del Medicamento también la autorizó para Europa, del mismo modo que en otros países o estados, para su propio consumo interno, como China y posiblemente Corea. Taiwán también solo para su población. Las RAM señaladas aquí corresponden al producto empleado en Lima y otros países, aunque ocasionalmente se señalan las de otros fabricantes a modo de comparación.

En Perú, la vacunación se inició en el segundo trimestre de 2010, cuando la vacuna estaba lista. Porque había pasado la onda pandémica, muchos no aceptaron ser vacunados, por temor sobre la inocuidad de la vacuna; los medios de comunicación estaban informando de RAM graves en el hemisferio norte. Argumentaban además que no era necesaria la vacunación, al haber remitido la epidemia; así mismo, que ya habían adquirido la influenza en forma leve, que la influenza era benigna, que tenían desconfianza múltiple, o porque no eran personas en riesgo. No eran 'antivacunicistas', porque habían utilizado antes otras vacunas. En términos generales, se observó que no despertó compromiso en la sociedad, siendo necesaria en especial para algunos sectores, por lo que se vacunó o se sugirió vacunar a las personas en riesgo, gestantes, niños y adultos jóvenes, personas con enfermedades subyacentes cardiovasculares, respiratorias, diabéticos, obesos, pero también sanos, incluyendo los trabajadores de salud. Las vacunas contra la influenza previenen esa infección, evitan complicaciones de los sujetos en riesgo y contribuyen al ahorro en recursos de salud, esperando que la vacunación alcance a todos los susceptibles y sean utilizadas oportunamente. La vacunación concluyó a fines de julio, al borde del vencimiento del producto.

Las vacunas A(H1N1) 2009 pueden ser consideradas productos nuevos, por no ser habitual su empleo como monovalentes y haber sido autorizadas para su producción en una situación excepcional de emergencia, de acuerdo a un Protocolo de rapidez pandémica, por lo que ameritaba la farmacovigilancia. De otro lado, respecto a las reacciones adversas a medicamentos (RAM), ninguna metodología para determinar la relación causa-efecto es universalmente aceptada, aunque se admite que son útiles por aproximarse a la verdad.
En algunos casos históricos, la relación causa-efecto ha sido tan evidente que no ha necesitado mayor demostración. Para el caso de las vacunas, al parecer el régimen de indemnización por RAM no es similar al de los medicamentos de estructura química conocida, por lo que algunos gobiernos expresaron dudas en asumir las responsabilidades por las RAM que podría producir la vacuna monovalente para la influenza pandémica; pero, se esperaba que en personas sanas o en riesgo no causaría más daño que la enfermedad que se pretendía prevenir.

La finalidad del presente estudio fue evaluar las notificaciones espontáneas sobre RAM de los trabajadores de salud del local central del INS en Lima, dentro de las 48 horas de haber recibido la vacuna para la influenza $\mathrm{A}(\mathrm{H} 1 \mathrm{~N} 1)$ 2009, en razón que en ese período se presentaron las notificaciones espontáneas. Además, comentar algunos tópicos por su relación con las RAM.

\section{MÉTODOS}

En mayo del 2010, se invitó a los trabajadores de salud de la dependencia central del INS de Perú a vacunarse contra la influenza A(H1N1) 2009. Para objeto del presente trabajo prospectivo y descriptivo basado en la notificación espontánea, se definió como trabajadores de salud a las personas que laboraban en esa dependencia, incluyendo médicos, biólogos, técnicos, enfermeras, veterinarios, personal administrativo y personal de vigilancia. En tal dependencia central se ofrece consejería a pacientes con VIH, se obtienen muestras de sangre para pruebas de laboratorio, se ejecutan diversos ensayos de laboratorio clínico, se aplican vacunas a personas que acuden al Centro de Vacunación Internacional (CVI), entre otras actividades análogas. En ese último Centro fue ejecutada la vacunación a los trabajadores de salud.

La vacuna fue administrada por vía intramuscular en el deltoides, con jeringuillas desechables de $1 \mathrm{~mL}$, en dosis 
única de 0,25 mL, desde un vial multidosis con $5 \mathrm{~mL}$. La marca registrada del producto fue Celtura 'vacuna contra la gripe pandémica H1N1'. La fecha de vencimiento 06 del 2010 constaba en la etiqueta del vial. En la etiqueta del vial e inserto no constaba que tuviera adyuvante, por lo cual debe admitirse que no lo tenía.

La OIS tomó conocimiento sobre molestias atribuidas a la vacunación por expresión directa o indirecta de tres trabajadores a modo de notificación espontánea y dentro de las 48 horas de aplicada la vacuna, por lo que se les invitó a llenar una hoja de reacciones adversas en base a una empleada por primera vez en el Ministerio de Salud (17), que para el presente trabajo fue considerada adecuada. Cuando fue necesario, se entrevistó a quienes llenaron dicha hoja de reacciones adversas, que incluía la aceptación de los datos por parte de los notificadores para publicación, aunque sin especificar nombre alguno. Una breve anamnesis y confirmación clínica fue realizada si se requería para confirmar datos; sin embargo, no se realizó intervención alguna para exámenes auxiliares o de laboratorio. No se realizó seguimiento de todas las otras personas vacunadas, en razón que al haber expectativas por supuestas presentaciones de reacciones adversas tal vez ocurriría un sesgo de información acopiada, denominada también 'autobservación somática excesiva'; por lo que se prefirió evaluar solamente cuando existían expresiones espontáneas, como los casos señalados. Hasta un mes después de la vacunación, no llegó otra notificación espontánea a la OIS ni al CVI, considerando que si se hubiera presentado algo significativo se habría difundido sin duda en la conversación diaria, por pertenecer a la misma dependencia central, y habrían acudido a la OIS o al CVI. Así, el objeto del estudio se circunscribió solamente a la información llegada espontáneamente por los vacunados.

Los datos de cada Hoja fueron sometidos a un algoritmo (figura 1), en base a uno utilizado previamente ${ }^{(18,19)} \mathrm{a}$

1. ¿Es la manifestación clínica o médica supuestamente RAM producida por la vacuna, aceptada como una reacción adversa al medicamento?
( ) $\mathrm{S} \mid$
Ir a la pregunta 2.
( ) NO o DK Ir a la pregunta 3 (DK = "desconocido")
[Puntaje: 2]
[Puntaje: 0$]$

2. ¿Se conoce que la característica clínica reportada ocurre en la dosis recibida en este caso?

$\begin{array}{lll}(\text { ) SI } & \text { Ir a la pregunta 3 } & \text { [Puntaje 2] } \\ \text { ( ) NO o DK } & \text { Ir a la pregunta 4 } & \text { [Puntaje 1] }\end{array}$

3. ¿Hay la suficiente experiencia acumulada con la vacuna como para asumir que la mayoría de sus RAM ya han sido reportadas en otros lugares?

( ) SI Ir a la pregunta 5

( ) NO Ir a la pregunta 4

[Puntaje 1]

[Puntaje 2]

4. ¿Puede considerarse la manifestación clínica supuesta RAM una complicación de una condición preexistente?
( ) Sl
Ir a la pregunta 6
( ) NO
Ir a la pregunta 5
[Puntaje 0]
[Puntaje 2]

5. Considerando el tipo de manifestación clínica supuestamente RAM ifue el tiempo desde la administración a la presentación, consistente 0 esperado para una RAM de esta vacuna?

( ) SI Ir a la pregunta 6

() NO Ir a la pregunta 6

[Puntaje 2]

[Puntaje 0]

6. ¿Hay evidencia demostrada que las manifestaciones clínica RAM se debe a una sobredosis de la vacuna?

( ) $\mathrm{SI}$

( ) NO

[Puntaje 0]

[Puntaje 2]

$\begin{array}{lll}\begin{array}{l}\text { Resultado } \\ \text { numérico }\end{array} & & \begin{array}{l}\text { Relación } \\ \text { causa - efecto } \\ 11 \text { y } 12\end{array} \\ \text { 8 a } 10 & \ldots \ldots \ldots \ldots \ldots \ldots \ldots . & \text { Cierta } \\ \text { 6 a } 7 & \ldots \ldots \ldots \ldots \ldots \ldots \ldots \ldots & \text { Probable } \\ <6 & \ldots \ldots \ldots \ldots \ldots \ldots \ldots \ldots & \text { Posible } \\ \text { < } & \ldots \ldots \ldots \ldots \ldots \ldots \ldots & \text { Improbable }\end{array}$

Figura 1. Algoritmo para determinar la relación causa-efecto de las reacciones adversas a la vacuna para la influenza $A\left(\mathrm{H}_{1} \mathrm{~N} 1\right) 2009$.

fin de obtener la relación causa-efecto en cuatro determinaciones: cierta, posible, probable, improbable. Además, los datos fueron revisados para opinión consensuada por expertos. No se tuvo conocimiento de RAM severas o graves en el resto del personal vacunado en el local, al menos hasta un mes después de la vacunación.

En todo momento se consideró los principios éticos y valores de protección al humano. El trabajo no incluyó aspectos de intervención.

\section{RESULTADOS}

Se presentaron voluntariamente a la vacunación 148 trabajadores adultos, constituidos por 74 hombres y 74 mujeres, en un rango de edad entre 22 a 64 años (tabla 1). Se amplió la información en dos de las tres personas que presentaron las notificaciones espontáneas, a fin de confirmar sus datos y sus manifestaciones clínicas. Una acudió a un hospital tres días después, en razón de presentar manifestaciones de infección respiratoria alta febril y también para el control de un proceso hipertensivo.

La notificación espontánea de RAM presentada por tres trabajadoras por sintomatología local y general atribuida a la vacunación, consistió en dos casos en fiebre $\geq 38^{\circ} \mathrm{C}$, con relación causaefecto 'cierta'. Una refirió también dolor intenso en el lugar de la aplicación. Además, una manifestó 'dolor de garganta', en la segunda 'molestia catarral' y en la tercera 'secreción respiratoria', que no las habían tenido antes de la vacunación, y que en conjunto fueron 
Tabla 1. Edad de los voluntarios vacunados contra la influenza $A\left(\mathrm{H}_{1} \mathrm{~N}_{1}\right) 2009$.

\begin{tabular}{|c|c|c|c|}
\hline Grupos etarios & Masculino & Femenino & Total \\
\hline 21 a 30 & 18 & 20 & 38 \\
\hline 31 a 40 & 21 & 15 & 36 \\
\hline 41 a 50 & 14 & 20 & 34 \\
\hline 51 a 60 & 13 & 19 & 32 \\
\hline 61 a 70 & 8 & - & 8 \\
\hline Total & 74 & 74 & 148 \\
\hline
\end{tabular}

calificadas como 'afecciones respiratorias'. Estas manifestaciones ocurrieron a los dos días o justo después de dos días a partir de la vacunación. Si consideramos la Clasificación Internacional de Enfermedades (CIE) de la OMS (http://apps.who.int/classifications/apps/icd/icd10online/), se puede asumir que tales reacciones adversas 'dolor de garganta', 'molestia catarral' y 'secreción respiratoria' corresponden a faringitis aguda, catarro nasal agudo y bronquitis catarral, respectivamente. Consideradas separadamente o en conjunto como 'afecciones respiratorias', la relación causa-efecto resultó como 'probable'. La opinión consensuada de expertos fue coincidente con tales resultados (tabla 2). Las tres personas emplearon tratamiento sintomático.

\section{DISCUSIÓN}

Para intentar explicar la aparición de la epidemia en la estación de primavera del hemisferio norte, tal vez se podría considerar que los virus de influenza que causan pandemia son capaces de tener un desarrollo epidemiológico algo diferente por sus características fenotípicas ${ }^{(20)}$.

En todos los países en que se utilizó las vacunas monovalentes $\mathrm{A}(\mathrm{H} 1 \mathrm{~N} 1)$ 2009, la relación riesgo-beneficio continuó a favor de las vacunas; de otro modo no hubieran sido empleadas. Sin embargo, se presentaron algunas RAM severas o graves por vacunas $\mathrm{A}(\mathrm{H} 1 \mathrm{~N} 1)$ 2009 en Corea, donde resultaron 29 personas con G-B semanas después de la administración ${ }^{(21)}$ y lo mismo en dos adultos en Sao Paulo ${ }^{(22)}$, así como neuritis óptica bilateral y encefalomielitis en un niño sano con dos dosis de dicha vacuna ${ }^{(23)}$. En Francia, las vacunaciones se iniciaron en octubre de 2009 para los trabajadores de salud de un hospital, pero durante la primera semana solo acudieron 129 trabajadores, de $187{ }^{(24)}$. Los países europeos redujeron sus pedidos de vacunas, encontrándose en el análisis de la reticencia a vacu- narse ${ }^{(25)}$ que la principal causa fue la falta de confianza en la seguridad de las vacunas.

En el presente estudio, encontramos RAM en tres personas sobre 148 vacunados, que es un $2 \%$, porcentaje diferente a lo encontrado en otras vacunas de influenza estacional trivalente o incluso monovalentes, en que suele ser mayor. Ello puede explicarse porque los porcentajes mayores suelen darse en farmacovigilancia o vigilancia intensiva, que no fue este el caso. Aquí existió notificación espontánea de los usuarios, no del prescriptor. Pero además, no debería extrapolarse los porcentajes de RAM que se encuentra en vacunas trivalentes frente a monovalentes, habiendo señalado que este producto monovalente debería ser considerado como producto nuevo, con limitada experiencia en su aplicación, que será difícil que vuelva a elaborarse ya que, de ser necesario, se incorporaría en las vacunas trivalentes usuales.

Una RAM reportada en este trabajo fue la fiebre en $1,35 \%$ de los vacunados, en una relación causa-efecto 'cierta', que no siendo porcentaje alto ha ocurrido con otras vacunas monovalentes para influenza producidas por otras empresas. La disimilitud con otras vacunas monovalentes que produjeron la RAM fiebre en diferentes porcentajes puede deberse, además del sistema de vigilancia, a las diferencias sutiles en las fabricaciones. En China ${ }^{(26)}$, la fiebre por la vacuna fue de menor frecuencia;

Tabla 2. Reacciones adversas presentadas después de la vacunación contra la influenza $A\left(\mathrm{H}_{1} \mathrm{~N} 1\right) 2009$ con la vacuna Celtura en tres notificaciones espontáneas.

\begin{tabular}{|c|c|c|c|c|c|c|}
\hline \multicolumn{7}{|c|}{ Sintomatología dentro de las 48 horas } \\
\hline \multicolumn{3}{|c|}{ Local } & \multicolumn{4}{|c|}{ General } \\
\hline RAM & $\mathrm{N}^{\circ}$ de casos & $\begin{array}{l}\text { Relación } \\
\text { causa-efecto }\end{array}$ & RAM & $\mathrm{N}^{\circ}$ de casos & $\begin{array}{l}\text { Relación } \\
\text { causa-efecto }\end{array}$ & $\%$ de los vacunados \\
\hline \multirow[t]{4}{*}{ Dolor intenso } & \multirow[t]{4}{*}{1} & \multirow[t]{4}{*}{ Cierta } & Fiebre $\geq 38^{\circ} \mathrm{C}$ & 2 & Cierta & 1,35 \\
\hline & & & Fatiga & 1 & Cierta & 0,67 \\
\hline & & & Dolor de articulaciones & 1 & Probable & 0,67 \\
\hline & & & $\begin{array}{l}\text { 'Afección respiratoria' (*dolor de garganta, } \\
{ }^{* *} \text { molestias catarrales, }{ }^{* * *} \text { secreción bronquial) }\end{array}$ & 3 & Probable & 2,02 \\
\hline
\end{tabular}

En concordancia con la Clasificación Internacional de Enfermedades de la OMS, corresponden a: * faringitis aguda; ** catarro nasal agudo; $y$ *** bronquitis catarral. 
de alrededor de dos millones de vacunados se informó que solo ocurrió en 176 casos. De modo diferente, considerando la respuesta de niños en Holanda ${ }^{(27)}$, el 56\% (359/639) que recibió la vacuna por primera vez hizo fiebre; con la segunda dosis de refuerzo presentó nuevamente fiebre el 56\% (213/380), lo que podría indicar que la RAM fiebre es persistente en la misma persona por el mismo producto. Esto último haría preguntar si existiría un riesgo adicional para quienes habiendo recibido la vacuna A(H1N1) 2009 monovalente y presentaron RAM, la reciban nuevamente con la actual trivalente estacional que la tiene incorporada.

Las RAM 'afecciones respiratorias' de nuestro trabajo se basaron en la descripción clínica, pero no se practicó estudios de laboratorio ni análogos por no corresponder a un protocolo de seguimiento clínico, solo la descripción de reacciones adversas, e incluimos en ellos el 'dolor de garganta' (faringitis aguda en la CIE de la OMS), 'molestias catarrales' (catarro nasal agudo en la CIE) y 'secreción bronquial' (bronquitis catarral en la CIE), al formar parte del mismo perfil que afecta al aparato respiratorio, alcanzando un porcentaje de $2 \%$ y una relación causa-efecto 'probable'. A ese respecto, en la evaluación del CDC, en las primeras reacciones adversas reportadas al Vaccine Adverse Event Reporting System (VAERS), tales 'afecciones respiratorias'. como fueron calificadas en dicha evaluación, alcanzaron el $10 \%$, aunque en un universo mucho mayor ${ }^{(28)}$. De todos modos, en nuestro trabajo las RAM 'afecciones respiratorias' se presentaron en mujeres, aunque por el universo relativamente pequeño de casos no se demostró diferencia significativa con los varones.

En un estudio en España sobre reacciones adversas de la vacuna $\mathrm{A}(\mathrm{H} 1 \mathrm{~N} 1)$ sin adyuvante, en 346 trabajadores de salud ${ }^{(29)}$, se encontró un porcentaje mucho mayor de RAM que en nuestro trabajo. Ello debe ser atribuido, como se ha señalado, al sistema de vigilancia intensiva en tales trabajadores, metodología que con alguna frecuencia no distingue exactamente la real reacción adversa al medicamento de una posible sintomatología producto de una 'autobservación somática excesiva', como lo señalan tales autores. Ello contribuiría a explicar además que, por la situación de una vacuna monovalente para esa epidemia y por la información mediática diversa sobre RAM graves, posiblemente se originó un incremento de percepción de manifestaciones adversas y de las notificaciones. Todo esto hace presumir que los trabajadores que presentaron RAM en nuestro trabajo y que acudieron espontáneamente para la notificación, porque no se había establecido para los trabajadores un seguimiento para reacciones adversas, realmente presentaron tales efectos adversos, sintomatología significativa que no fue leve, tanto que una de ellas requirió atención médica ambulatoria en un hospital general, aunque ninguna RAM fue considerada grave. Las RAM constituyen un problema de salud pública ${ }^{(30)}$, no siendo fácil acopiar datos; pero, para esta vacuna existió cierto incremento de notificaciones espontáneas en varios países, encontrando en ellos un incremento de informes RAM de más de 30\% que en el $2008{ }^{(31)}$.

En China, en 89 millones de vacunados ${ }^{(32)}$, un grupo de 1063 presentó 'enfermedad coincidente' como evento adverso, que incluyó las 'infecciones respiratorias altas' por tal vacunación monovalente. Ello significa la posibilidad que tales vacunas puedan producir o promover, en mayor o menor magnitud, manifestaciones respiratorias no infecciosas e infecciosas. En otro estudio de datos del VAERS de EE UU (33) para tal vacuna monovalente, se encontró como reacciones adversas 'afecciones respiratorias', incluyendo las de garganta y enfermedad seudogripal. En nuestro trabajo, por las características en que se presentaron las notificaciones, no se consideró ordenar exámenes auxiliares.

De otro lado, es posible admitir que diferentes RAM en una misma persona puedan tener en una RAM relación causa-efecto 'cierta' y en otra
RAM 'probable', debido en parte a la frecuencia de presentación en otros estudios, lo que influye en el algoritmo. En consecuencia, es de esperar que la mayoría tenga varios síntomas y signos RAM a la vez, con predominancia de la fiebre ${ }^{(34)}$. De otro lado, la RAM fatiga y dolores articulares fueron transitorias y se las ha descrito con estas vacunas o análogas. En estos productos nuevos, en un universo cada vez mayor por la prescripción y con el tiempo de empleo, se confirmaría o hasta surgirían nuevas RAM no descritas inicialmente. Esto último podría corresponder a la narcolepsia de 162 niños y adolescentes en Europa, atribuida como RAM de una vacuna A(H1N1) 2009 monovalente ${ }^{(35)}$, tiempo después de su administración.

En el presente trabajo, la RAM fiebre se presentó en dos mujeres y no en hombres. Al respecto podría considerarse que ellos no reportarían la fiebre ni el dolor local, por un rasgo varonil y facilidad en utilizar medicación sintomática de venta sin receta médica sugerida por los vacunadores. Eso no sería aplicable a las 'afecciones respiratorias', por ser compleja la automedicación, la cual no es sugerida para estos medicamentos por los vacunadores. Tales RAM 'afecciones respiratorias', con el mismo número de vacunados hombres y mujeres, fueron más frecuentes en mujeres; sin embargo, con tal universo no fue posible confirmarlo estadísticamente, pero constituyó una tendencia. Tal tendencia de reacciones adversas para las vacunas en el género femenino podría haber sido demostrada o ser significativa tal vez con un universo mayor, considerando que el género femenino fue un posible factor de riesgo para la influenza A(H1N1) $2009^{(36)}$ y en razón que la vacuna corresponde a su derivado biológico viral. En un estudio con un universo de vacunados mayor, de cuatro mil militares, se encontró que el género femenino fue un factor de riesgo para la ocurrencia de eventos adversos después de la vacunación contra la influenza A(H1N1) $2009^{\text {(37) }}$, lo que afirma que nuestro hallazgo de la 
tendencia fue relevante. En agosto de 2010 se declaró el fin de la pandemia.

Se concluye señalando que, en 148 trabajadores de salud de una institución en Lima que recibieron la vacuna monovalente contra la influenza A(H1N1) 2009 se encontró que las RAM 'afecciones respiratorias' alcanzaron el 2\%, siendo más frecuentes en mujeres que en hombres, diferencia no significativa atribuida al escaso universo. Sin embargo, podría sugerir alguna predisposición a determinadas reacciones adversas, las que resultaron como 'posible' en la evaluación. Las RAM fiebre, fatiga y dolor articular son coincidentes con otros estudios para la vacuna empleada. Se discute aspectos sobre el virus, la epidemia, así como la probable protección de los adultos mayores a la pandemia, entre otros tópicos afines.

\section{REFERENCIAS BIBLIOGRÁFICAS}

1. Osztovits J, Balázs $\mathrm{C}$, Fehér J. H1N1 influenza-pandemic, 2009. Orv Hetil. 2009;150(50): 2265-73.

2. Grouse LD. Swine flu sequelae. JAMA. 1980;243(24):2489.

3. Smith GJ, Vijaykrishna D, Bahl J, Lycett SJ, Worobey M, Pybus OG, et al. Origins and evolutionary genomics of the 2009 swine-origin $\mathrm{H} 1 \mathrm{~N} 1$ influenza A epidemic. Nature. 2009;459(7250):1122-5.

4. Zimmer SM, Burke DS. Historical perspective- Emergence of influenza $A(\mathrm{H} 1 \mathrm{~N} 1)$ viruses. N Engl J Med. 2009;361(3):279-85.

5. Dominguez-Cherit G, Lapinsky SE, Macias AE, Pinto $R$, Espinosa-Perez $L$, de la Torre $A$, et al. Critically III patients with 2009 influenza $\mathrm{A}(\mathrm{H} 1 \mathrm{~N} 1)$ in Mexico. JAMA. 2009;302(17):1880-7.

6. Dawood FS, Jain S, Finelli L, Shaw MW, Lindstrom S, Garten RJ, et al. Emergence of a novel swine-origin influenza $\mathrm{A}\left(\mathrm{H}_{1} \mathrm{~N}_{1}\right)$ virus in humans. N Engl J Med. 2009;360(25):2605-15.

7. Centers for Disease Control and Prevention (CDC). Serum cross-reactive antibody response to a novel influenza $\mathrm{A}\left(\mathrm{H}_{1} \mathrm{~N} 1\right)$ virus after vaccination with seasonal influenza vaccine. MMWR Morb Mortal Wkly Rep. 2009;58(19):521-4.

8. Kelly H, Grant K. Interim analysis of pandemic influenza (H1N1) 2009 in Australia: surveillance trends, age of infection and effectiveness of seasonal vaccination. Euro Surveill. 2009;14(31):1-5.

9. Hancock K, Veguilla V, Lu X, Zhong W, Butler EN, Sun $\mathrm{H}$, et al. Cross-Reactive Antibody Responses to the 2009 Pandemic H1N1 Influenza Virus. N Engl J Med. 2009;361(20):1945-52.

10. Alvarez-Falconi PP, Ríos Ruiz BA. Oropuche fever outbreak in Bagazan, San Martin, Peru: epidemiological evaluation, gastrointestinal and hemorrhagic manifestations. Rev Gastroenterol Peru. 2010:30(4):334-40.
11. Diaz C, Moreno D, Alemán AC, Salazar BN. Perfil clínico y epidemiológico de la influenza $\mathrm{A} H 1 \mathrm{~N} 1$ en el Hospital Nacional Almanzor Aguinaga Asenjo. Acta méd per. 2010;27(2):81-90.

12. Morens DM, Taubenberger JK, Fauci AS. The persistent legacy of the 1918 influenza virus. N Engl J Med. 2009;361(3):225-9.

13. Nelson MI, Viboud C, Simonsen L, Bennett RT Griesemer SB, St. George K, et al. Multiple reassortment events in the evolutionary history of $\mathrm{H} 1 \mathrm{~N} 1$ influenza $\mathrm{A}$ virus since 1918. PLoS Pathog. 2008;4(2):e1000012.

14. Farley MM. 2009 H1N1 influenza: a twenty-firs century pandemic with roots in the early twentieth century. Am J Med Sci. 2010;340(3):202-8.

15. Tang JW, Shetty N, Lam TT. Features of the new pandemic influenza $\mathrm{A} / \mathrm{H} 1 \mathrm{~N} 1 / 2009$ virus: virology, epidemiology, clinical and public health aspects. Curr Opin Pulm Med. 2010;16(3):235-41.

16. Collignon PJ. A pandemic response to a disease of predominantly seasonal intensity. Med J Aust. 2010;192(6):358.

17. Alvarez PP. Reacciones adversas a medicamentos (RAM) y farmacovigilancia: I método algorítmico. Bo Inst Nac Salud. (Lima) 1986;7(1-4):32-9.

18. Alvarez-Falconí PP. Influencia de medicamentos con reacciones adversas trombocitopénicas. Rev Farmacol Terap (Lima). 1992;2(1):10-1.

19. Alvarez-Falconi PP. Reacciones adversas a medicamentos en muestras de pacientes ambulatorios y hospitalizados. Rev Farmacol Terap (Lima). 1999;6(12):69-71.

20. Kiseleva I, Larionova N, Kuznetsov V, Rudenko L. Phenotypic characteristics of novel swine-origin influenza A/California/07/2009 (H1N1) virus. Influenza Other Respi Viruses. 2010;4(1):1-5.

21. Choe YJ, Cho H, Bae GR, Lee JK. Guillain-Barré syndrome following receipt of influenza $A\left(\mathrm{H}_{1} \mathrm{~N}_{1}\right)$ 2009 monovalent vaccine in Korea with an emphasis on Brighton Collaboration case definition. Vaccine. 2011;29(11);2066-70.

22. Marin LF, Abrahão A, Carvalho FA, Santos WAC Dallalba CC, Barcelos LB, et al. Guillain-Barré syndrome associated with $\mathrm{H}_{1} \mathrm{~N} 1$ vaccination. Arq Neuropsiquiatr. 2010;68(6):974-5.

23. Lapphra K, Huh L, Scheifele DW. Adverse neurologic reactions after both doses of pandemic $\mathrm{H}_{1} \mathrm{~N}_{1}$ influenza vaccine with optic neuritis and demyelination. Pediatr Infect Dis J. 2010;30(1):84-6.

24. Dinh A, Lawrence C, Salomon J, Descatha A Expected and unexpected adverse effects $\mathrm{H}_{1} \mathrm{~N} 1$ vaccination for health care workers in a university hospital. Vaccine. 2010;28(9):2063.

25. Steelfisher GK, Blendon RJ, Bekheit MM, Lubell K. The public's response to the $2009 \mathrm{H} 1 \mathrm{~N} 1$ influenza pandemic. N Engl J Med. 2010;362(22):e65(1)e65(6).

26. Miao L, Lu L, Wu J, Suo LD, Liu DL, Sun MP, et al. Analysis of adverse events following 2009 influenza $A(H 1 N 1)$ vaccinoprophylaxis in Beijing. Zhonghua Yu Fang Yi Xue Za Zhi. 2010;44(10):884-7.

27. Broos N, Van Puijenbroek EP, Van Grootheest K. Fever following immunization with influenza $A\left(\mathrm{H}_{1} \mathrm{~N} 1\right)$ vaccine in children: a survey-based study in the Netherlands. Drug Saf. 2010;33(12):1109-15.

28. Centers for Disease Control and Prevention (CDC). Safety of influenza A ( $\left.\mathrm{H}_{1} \mathrm{~N}_{1}\right) 2009$ monovalent vaccines - United States, October 1-November 24, 2009. MMWR Morb Mortal Wkly Rep. 2009;58(48):1351-6.
29. Sánchez-Payá J, Hernández-Garcia I, BarrenengoaSañudo J, Camargo-Angeles R, Rincon A, RomeroCandeira S. Frecuencia de reacciones adversas y factores asociados tras la administración de la vacuna de la gripe en personal sanitario durante la temporada 2009-2010. Rev. Esp. Salud Publica. 2010;84(6):851-9.

30. Alvarez-Falconi PP. Decisiones en reacciones adversas a medicamentos, intoxicaciones y respuestas inesperadas de productos naturales como problema de salud pública. Rev Peru Med Exp Salud Publica. 2007;24(4):405-26.

31. Mahajan D, Campbell-LLoyd S, Roomiani I, Menzies RI. NSW Annual Adverse Events Following Immunisation Report, 2009. N S W Public Health Bull. 2010;21(9-10):224-33.

32. Liang XF, Li L, Liu DW, Li KL, Wu WD, Zhu BP, et al. Safety of Influenza $A\left(\mathrm{H}_{1} \mathrm{~N}_{1}\right)$ Vaccine in Postmarketing Surveillance in China. N Engl J Med. 2011;364(7):638-47.

33. Vellozzi C, Broder KR, Haber P, Guh A, Nguyen M, Cano $\mathrm{M}$, et al. Adverse events following influenza $A$ (H1N1) 2009 monovalent vaccines reported to the Vaccine Adverse Event Reporting System, United States, October 1, 2009-January 31, 2010. Vaccine. 2010;28(45):7248-55.

34. Petrović V, Seguljev Z, Medić S, Ristić M, Tomić S, Cvetić $\mathrm{G}$. Analysis of suspected adverse reactions following immunization against pandemic influenza. Med Pregl. 2011;64(5-6):305-9.

35. Zarocostas J. WHO backs further probes into possible link between $\mathrm{H} 1 \mathrm{~N} 1$ vaccine and narcolepsy in children. BMJ. 2011;342:d909.

36. Choi SH, Chung JW, Jeon MH, Lee MS. Risk factors for pandemic H1N1 2009 infection in healthcare personnel of four general hospitals. J Infect. 2011; May 1. (In Press, Corrected Proof, Available online 1 May 2011).

37. Hwang SM, Choe KW, Cho SH, Yoon SJ, Park DE, Kang JS, et al. The adverse events of influenza A $(\mathrm{H} 1 \mathrm{~N} 1)$ vaccination and its risk factors in healthcare personnel in 18 military healthcare units in Korea. Jpn J Infect Dis. 2011;64(3):183-9.

\section{Conflictos de interés:}

Los autores no tienen conflicto de interés en relación al estudio reportado en este artículo.

\section{Agradecimiento:}

Al Dr. José Bisbal Birot, Coordinador del Centro de Vacunación Internacional del Instituto Nacional de Salud, por la confirmación del número de vacunados y vacuna empleada.

Correspondencia:

Dr. Pedro P. Alvarez-Falconi

Dirección: Instituto Nacional de Salud.

Jr. Cápac Yupanqui 1400, Jesús María

Lima. Perú

e-mail: catecol@hotmail.com. 